Original Research Article

\title{
A study on adverse drug reactions in patients on antiretroviral therapy in a tertiary care hospital
}

\author{
Praveena Gungam¹, Y. Sunil Kumar Yadav ${ }^{1 *}$, Sunil Junapudi²
}

\begin{abstract}
${ }^{1}$ Department of Pharmacology, Osmania Medical College, Koti, Hyderabad, Telangana 500095, India

${ }^{2}$ Department of Pharmaceutical Chemistry, Geethanjali College of Pharmacy, Cherryal, Keesara, Medchal, Telangana 501301, India
\end{abstract}

Received: 10 August 2018 Accepted: 31 August 2018

*Correspondence to:

Dr. Y. Sunil Kumar Yadav, Email: ysunil.omc@gmail.com

Copyright: () the author(s), publisher and licensee Medip Academy. This is an openaccess article distributed under the terms of the Creative Commons Attribution NonCommercial License, which permits unrestricted noncommercial use, distribution, and reproduction in any medium, provided the original work is properly cited.

\begin{abstract}
Background: Besides unparalleled advantages, exceptionally dynamic antiretroviral treatment is additionally connected with extensive variety of potential adverse drug reactions (ADRs), which prevents treatment adherence. The present study is intended to screen and monitor the event of ADRs to different antiretroviral treatment (ART) regimens in a tertiary care ART setup.

Methods: A prospective, longitudinal observational study was done in the outpatient setting of nodal ART center, Osmania General Hospital. A sum of 525 patients on different ART regimens were examined for ADRs more than year and a half. Adverse event history, prescription history and other significant subtle elements were captured. Causality and seriousness of each announced ADR were surveyed.

Results: $37.33 \%$ patients of aggregate members gave a sum of 330 ADRs. Patients from zidovudine-based regimens presented with majority of ADRs such as anemia, central nervous system (CNS), and gastrointestinal (GI) side effects. Tenofovir-based regimens were, be that as it may, observed to be somewhat more secure. The blend with Efavirenz was related with significant CNS reactions while that of Nevirapine was related with rash and pigmentation of nails. Atazanavir supported second-line regimens were quite connected with expanded serum lipid levels taken after by other GI and CNS unfavourable impacts. Expanded liver compounds were found in atazanavir-based second-line ART. Conclusions: The study enables to obtain in sequence on the incidence and pattern of ADRs associated with various antiretroviral regimens, thereby reducing its occurrence and protecting the patient population from avoidable harm. Need of intensive monitoring for ADRs in ARTs along these lines is by all accounts an order.
\end{abstract}

Keywords: Antiretroviral, Adverse drug reactions, Human immunodeficiency virus, Tertiary care

\section{INTRODUCTION}

The human immunodeficiency infection (HIV) disease keeps on being a serious worldwide medical problem. Late measurements express that there were around 2.4 million new instances of HIV in 2017. Of around 36.9 million individuals living with HIV (PLHIV) around the globe, around 21.7 million individuals have been getting antiretroviral treatment (ART). ${ }^{1}$ The presentation of this treatment in the created nations in the late 90s and the ensuing advancement in giving its availability all around has been related with a striking abatement in AIDS-related mortality, which has changed the standpoint of HIV infection from being a quickly lethal to an incessantly reasonable infection. ${ }^{2,3}$ Antiretrovirals mainly suppress viral load, in this way re-establishing the insusceptible capacity. Declining expenses of antiretrovirals alongside the generation of medications by bland producers has helped tertiary care centers in resource limited territories 
cook better antiretroviral care to HIV-seropositive population. ${ }^{4,5}$

Despite showing considerable efficacy in reducing mortality and morbidity in PLHIV, ART is also associated with wide range of potential adverse effects leading to reduction in patient's quality of life and adversely affecting treatment adherence which may consequently lead to treatment failure. Adverse drug reactions (ADRs) to these medications remain a significant point of concern which may subsequently compromise the effectiveness of an ART program. ADRs due to continuous exposure to antiretroviral drugs leaves the caregiver with limited options such as decreasing the dosage of antiretroviral drugs, withdrawing the offending drug or substituting it with another drug or symptomatically treating the ADR(s). However, substituting the offending drug is cumbersome, especially in resource limited settings as most highly active antiretroviral therapy (HAART) regimens come as fixed dose combinations of different drugs having varied toxicity profiles. ${ }^{6,7}$

ADRs represent significant mortality and morbidity other than having immense economic impact on patients, healthcare suppliers and society. The majority of the ADRs are preventable. The rate of ADRs among patients on antiretrovirals from both creating and created nations goes somewhere in the range of $11 \%$ and $35.9 \%$ with rate being as high as $54 \%$ concurrent with astute disease. ${ }^{8-10}$ The long term impacts of antiretroviral solutions are to a great extent obscure however different continuous investigates are giving further bits of knowledge into some unfavourable responses of these medications. The present investigation was in this manner intended to screen and break down the example of event of ADRs to ART regimens in a tertiary care ART setup.

\section{METHODS}

A prospective, longitudinal, data-based clinical study was disbursed for about eighteen months (February 2016August 2017) in PLHIV receiving from Osmania General Hospital, Hyderabad. Institutional committee approval was taken before the initiation of the study and written consent was obtained from all subjects before their inclusion in the study. Confidentiality of knowledge was punctually maintained and basic principles of ethics in clinical analysis were strictly followed.

\section{Inclusion criteria}

- All consecutive treatment subjects

- $\quad$ Either sex aged eighteen years and above placed on ART

\section{Exclusion criteria}

- Subjects having treatment modifications or medicine failure

- $\quad$ Pregnant women, lactating mothers
- Patients having the other comorbidities like medicine ill health, diabetic mellitus, high blood pressure, chronic nephrosis, etc.

Patient demographics and clinical information were collected. Adverse event history, medication history and different relevant details were captured by a format as adopted within the pharmacovigilance programme of Republic of India. ADRs were assessed by Naranjo's ADR likelihood scale and WHO-UMC relation scale. The severity of every reportable ADR was assessed by Hartwig and Siegel Scale. Descriptive applied mathematics analysis of the obtained information was performed.

\section{RESULTS}

A total of 525 patients were screened for the study, of which males represented $51.80 \%(\mathrm{n}=272)$ of the population. Out of the total population, 110 males $(40.44 \%)$ and 86 females $(34 \%)$ presented with one or more ADRs. Thus, 196 patients $(37.33 \%)$ presented with 282 ADRs. As some patients had $>1$ ADR throughout constant visit, the whole range of ADRs was bigger than the whole range of patients experiencing a reaction. In cases wherever a regular reaction occurred over once within the same patient throughout the visit, the patient was documented as having full-fledged one reaction. Age bracket analysis discovered that patients inside the age bracket of 51-60 years bestowed with most ADRs, followed by $41-50$ years and 18-30 years, severally (Table 1).

\section{Table 1: Patients presenting with adverse drug reactions.}

\begin{tabular}{|lll|}
\hline & $\begin{array}{l}\text { Total patients } \\
\text { screened }\end{array}$ & $\begin{array}{l}\text { Total patients } \\
\text { presenting with ADRs }\end{array}$ \\
\hline 18-28 years & 126 & 48 \\
\hline 29-38 years & 282 & 96 \\
\hline 39-48 years & 89 & 37 \\
\hline 49-58 years & 22 & 13 \\
\hline$\geq 61$ years & 6 & 2 \\
\hline Total & 525 & 196 \\
\hline
\end{tabular}

ADRs $=$ Adverse drug reaction

Out of the three ART regimens prescribed under NACO program, zidovudine-based first-line beneficiaries $(40.30 \%)$ gave most extreme ADRs. Among the secondline regimens, zidovudine and supported atazanavir blend beneficiaries gave greatest ADRs. Out of 282 ADRs reported, zidovudine-nevirapine based first-line regimens $(37.9 \%)$ represented most extreme revealed ADRs taken after by zidovudine-efavirenz (EFV) -based regimens (27.65\%) (Table 2).

Evaluation of the aggregate ADR profile uncovered, sensory system issue representing the most extreme ADRs (26.36\%), followed by gastrointestinal (GI) (24.82\%) metabolism disorders (20.9\%) (Figure 1). 
Table 2: Total adverse drug reactions presented from various antiretroviral therapy regimens.

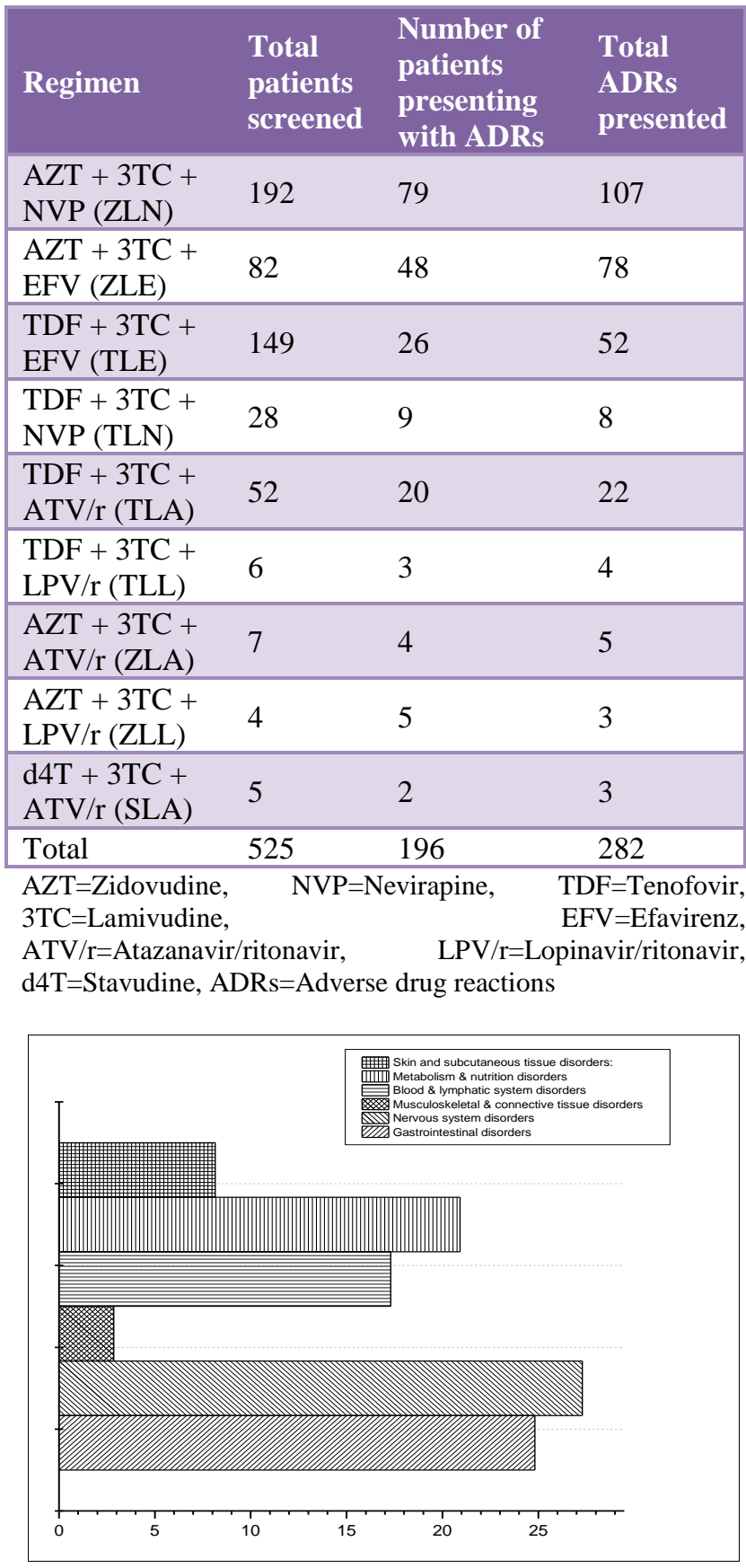

Figure 1: Spectrum of various reported adverse drug reactions.

Among different GI disorders, majority presented with complaints of nausea and increased liver enzymes. Insomnia and headache were the most detailed ADRs from sensory system. Different skin issues revealed as ADRs included rashes and nail pigmentation. Serious ADRs requiring clinic confirmation incorporate four instances of Stevens Johnson disorder. Expanded lipid level was the most ordinarily announced ADR (20.92\%), trailed by anemia (17.02\%) (Table 3).
Table 3: Frequency of various adverse drug reactions.

\begin{tabular}{|ll|}
\hline ADR description & \multicolumn{1}{l|}{ Frequency (\%) } \\
\hline \multicolumn{2}{|l|}{ Skin and subcutaneous tissue disorders: } \\
\hline Rashes & $15(5.31)$ \\
\hline SJS & $3(1.06)$ \\
\hline Pigmentation of nails & $5(1.77)$ \\
\hline Gastrointestinal disorders: \\
\hline Anorexia & $7(2.40)$ \\
\hline Nausea & $22(7.80)$ \\
\hline Vomiting & $10(3.54)$ \\
\hline Abdominal pain & $10(3.54)$ \\
\hline Abdominal cramps & $1(0.03)$ \\
\hline Diarrhea & $3(1.06)$ \\
\hline Gastric intolerance & $3(1.06)$ \\
\hline Increased liver enzyme levels & $14(4.96)$ \\
\hline Nervous system disorders: & \\
\hline Insomnia & $31(11)$ \\
\hline Giddiness & $1(0.03)$ \\
\hline Headache & $22(7.80)$ \\
\hline Peripheral neuropathy & $2(0.07)$ \\
\hline Numbness & $7(2.4)$ \\
\hline Tremors & $3(1.06)$ \\
\hline Dizziness & $6(2.12)$ \\
\hline Nightmares & $5(1.77)$ \\
\hline Musculoskeletal and connective tissue disorders: \\
\hline Generalized weakness & $1(0.03)$ \\
\hline Body ache & $6(2.12)$ \\
\hline Muscle cramps & $1(0.03)$ \\
\hline Blood and lymphatic system disorders: \\
\hline Anemia & $48(17.02)$ \\
\hline Pallor & $1(0.03)$ \\
\hline Metabolism and nutrition disorders: \\
\hline Increased lipid levels & $59.92)$ \\
\hline
\end{tabular}

Patients from zidovudine-based regimens such as ZLN and ZLE gave the lion's share of ADRs, such as anemia (up to $36 \%$ ), central nervous system (CNS) reactions and GI symptoms. Tenofovir-based regimens were observed to be somewhat more secure. Combination with EFV was related with significant CNS reactions while that of nevirapine was related with rash and pigmentation of nails. Lopinavir based second-line regimens were remarkably connected with expanded serum lipid levels taken after by other GI and CNS unfavourable impacts. Elevated liver enzymes were found in atazanavir based second-line ART (Table 4).

Out of 282 ADRs surveyed for causality utilizing Naranjo's algorithm and WHO UMC causality appraisal scale, 249 ADR cases $(88.29 \%)$ were observed to be "probable" while $33(11.71 \%)$ were observed to be "possible". 11-13 WHO-UMC causality evaluation scale indicated $81.91 \%(\mathrm{n}=231)$ as "probable/likely" and $14.53 \%(\mathrm{n}=41)$ as "conceivable." 
Seriousness was surveyed utilizing Hartwig and Siegels Scale, $82.53 \%$ of the cases were observed to be gentle while $15.92 \%$ and $1.55 \%$ of the cases were discovered direct and extreme, individually (Figure 2). ${ }^{14}$

Table 4: Distribution of various adverse drug reactions based on different antiretroviral therapy regimens.

\begin{tabular}{|c|c|c|c|c|c|c|c|c|c|}
\hline ADR description & $\begin{array}{l}\text { AZT+ } \\
\mathbf{3 T C} \\
\text { +NVP }\end{array}$ & $\begin{array}{l}\text { AZT+ } \\
3 T C \\
\text { +EFV }\end{array}$ & $\begin{array}{l}\text { TDF+ } \\
3 T C \\
+E F V\end{array}$ & $\begin{array}{l}\text { TDF+ } \\
\text { 3TC } \\
+ \text { NVP }\end{array}$ & $\begin{array}{l}\mathrm{TDF}+ \\
3 \mathrm{TC}+ \\
\mathrm{ATV} / \mathbf{r}\end{array}$ & $\begin{array}{c}\mathrm{TDF}+ \\
3 \mathrm{TC}+ \\
\mathrm{LPV} / \mathrm{r}\end{array}$ & $\begin{array}{l}\mathbf{A Z T}+ \\
\mathbf{3 T C}+ \\
\mathbf{A T V} / \mathbf{r}\end{array}$ & $\begin{array}{l}\mathrm{AZT}+ \\
3 \mathrm{TC}+ \\
\mathrm{LPV} / \mathbf{r}\end{array}$ & $\begin{array}{l}\text { d4T + } \\
3 T C+ \\
\text { ATV/r }\end{array}$ \\
\hline \multicolumn{10}{|c|}{ Skin and subcutaneous tissue disorders: } \\
\hline Rashes & 6 & 0 & 2 & 3 & 3 & 2 & 0 & 0 & 0 \\
\hline SJS & 0 & 0 & 2 & 2 & 2 & 0 & 0 & 0 & 0 \\
\hline Pigmentation of nails & 2 & 2 & 0 & 0 & 0 & 0 & 0 & 0 & 0 \\
\hline \multicolumn{10}{|l|}{ Gastrointestinal disorders: } \\
\hline Anorexia & 5 & 3 & 0 & 0 & 0 & 0 & 0 & 0 & 0 \\
\hline Nausea & 10 & 7 & 2 & 1 & 1 & 1 & 0 & 0 & 1 \\
\hline Vomiting & 4 & 4 & 2 & 1 & 1 & 1 & 0 & 1 & 0 \\
\hline Abdominal pain & 6 & 0 & 0 & 0 & 1 & 1 & 0 & 0 & 0 \\
\hline Abdominal cramps & 0 & 0 & 1 & 0 & 1 & 1 & 0 & 0 & 0 \\
\hline Diarrhea & 0 & 0 & 2 & 0 & 0 & 0 & 0 & 0 & 0 \\
\hline Gastric intolerance & 1 & 0 & 0 & 1 & 0 & 1 & 0 & 0 & 0 \\
\hline Increased liver enzyme levels & 0 & 0 & 1 & 0 & 0 & 8 & 2 & 0 & 0 \\
\hline \multicolumn{10}{|l|}{ Nervous system disorders: } \\
\hline Insomnia & 9 & 7 & 10 & 0 & 0 & 1 & 0 & 0 & 0 \\
\hline Giddiness & 0 & 0 & 1 & 1 & 0 & 0 & 0 & 0 & 0 \\
\hline Headache & 50 & 8 & 6 & 1 & 0 & 0 & 0 & 1 & 1 \\
\hline Peripheral neuropathy & 1 & 0 & 0 & 0 & 0 & 0 & 0 & 0 & 0 \\
\hline Numbness & 0 & 4 & 2 & 0 & 0 & 0 & 0 & 0 & 0 \\
\hline Tremors & 0 & 1 & 2 & 0 & 0 & 0 & 0 & 0 & 0 \\
\hline Dizziness & 0 & 0 & 4 & 0 & 0 & 0 & 0 & 0 & 0 \\
\hline Nightmares & 0 & 0 & 3 & 0 & 0 & 0 & 0 & 0 & 0 \\
\hline \multicolumn{10}{|c|}{ Musculoskeletal and connective tissue disorders: } \\
\hline Generalized weakness & 0 & 0 & 1 & 0 & 0 & 0 & 0 & 0 & 0 \\
\hline Body ache & 0 & 0 & 1 & 0 & 0 & 0 & 0 & 0 & 0 \\
\hline Muscle cramps & 0 & 0 & 0 & 0 & 0 & 0 & 0 & 0 & 0 \\
\hline \multicolumn{10}{|c|}{ Blood and lymphatic system disorders: } \\
\hline Anemia & 22 & 18 & 0 & 0 & 0 & 0 & 0 & 0 & 0 \\
\hline Pallor & 0 & 0 & 1 & 0 & 0 & 0 & 0 & 0 & 0 \\
\hline \multicolumn{10}{|c|}{ Metabolism and nutrition disorders: } \\
\hline Increased lipid levels & 21 & 12 & 8 & 1 & 6 & 3 & 2 & 1 & 2 \\
\hline
\end{tabular}
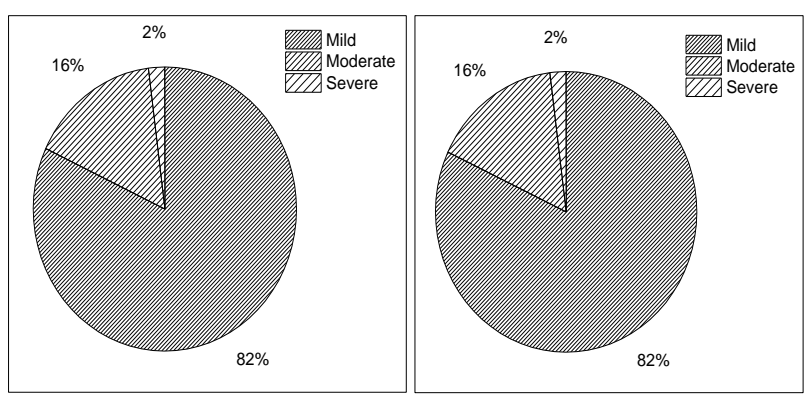

Figure 2: Causality and severity assessment of reported adverse drug reactions (as per Naranjo's Algorithm and Hartwig Seigel Scale, respectively).

\section{DISCUSSION}

With the introduction of HAART, a huge number of eligible HIV-infected patients are currently having better access to antiretroviral drugs; subsequently leading to considerable decrement in HIV-related morbidity and mortality globally. Be that as it may, the unfavourable impacts of these medications involve expanding worry in the treatment of PLHIV attributable to the need of keeping up ART uncertainly to accomplish clinical advantages. Unfavourable response to antiretrovirals in PLHIV is a noteworthy reason for non-adherence to treatment, prompting ensuing treatment disappointment. ${ }^{15-18}$ The 
present examination along these lines observed the ADR design in patients accepting antiretroviral treatment in a nodal ART mind focus.

The present study revealed that out of the three different antiretroviral regimens prescribed under NACO program, zidovudine-based first-line beneficiaries had greatest ADRs. Among the second-line regimens, zidovudine and atazanavir blend beneficiaries presented with most extreme ADRs. Zidovudine-nevirapine based first-line regimens represented most extreme revealed ADRs taken after by zidovudine-EFV based regimens.

ADRs involving nervous system represented the most extreme number, trailed by GI, and digestion issue. EFV regimen was significantly associated with CNS reactions, like sleep deprivation, cerebral pain, deadness, discombobulation, and so forth. For most patients, these side-effects settled within 5-12 weeks of beginning treatment, yet for a few patients, side effects appeared to wax and wind down long haul. CNS reactions by and large turn out to be more average and resolve inside the initial 5 weeks of treatment. EFV related unfavourable occasions may trade off adherence to treatment and prompt treatment cessation. A few examinations have announced treatment suspension rates extending from $4 \%$ to $46 \%$ identified with neuropsychiatric reactions of EFV. ${ }^{19-21}$ Clinicians should advise patients having conceivable CNS impacts of EFV and search for conduct and intellectual changes. If there should be an occurrence of persevering or horrendous symptoms, a switch in HAART regimen might be discovered proper. Regardless of being first-line treatment, numerous patients get EFV simply in the wake of encountering treatment disappointment on prior HAART regimens. In this manner, patients who change to EFV and after that experience neurologic or mental side-effects are left with constrained alternatives for future antiretroviral treatment. Watchful contemplations with respect to dangers and treatment options for these patients are required. . $2,23^{2}$

Among various GI issue, lion's share given protestations of sickness and elevated liver enzymes. Liver enzymes of fluctuating degree have been accounted for with all classes of affirmed antiretroviral drugs. Extreme instances of hepatotoxicity with lethal results have been accounted for with ARV treatment, and elevated liver enzymes have been a typical clinical explanation behind this treatment stopping in clinical practice. The instruments however vague significantly allude to mitochondrial lethality coming about because of nucleoside turn around transcriptase inhibitors (NRTIs) utilize and excessive responses to nonnucleoside switch transcriptase inhibitors (NNRTIs). ${ }^{24}$

In this set up, skin and subcutaneous tissue issues represented $8.14 \%$ of the aggregate ADRs. Different skin issues revealed as ADRs included rashes and nail pigmentation, which were significantly announced from nevirapine-based regimens, which are apparently invulnerable interceded reactions. Steven- Johnson disorder was seen in four patients, three of them were in nevirapine-based regimens while one was in EFV-based regimen. DE challenging and resulting regimen change over to EFV and nevirapine-based regimens, individually, were discovered effective. No rechallenge was anyway end eavored.

The present investigation demonstrated that lipid variations from the norm remained the greatest revealed ADR. It represented $20.92 \%$ of the aggregate ADRs. In vitro contemplates have proposed that protease inhibitors (PIs) may impact lipid digestion by meddling with the debasement by proteasomes in hepatocytes and adipocytes, affecting quality articulation engaged with lipid digestion. Particular PIs vary in their lipid impacts in vitro. Expanded lipid levels were found in helped PI based second-line. ${ }^{25,26}$ Atazanavir supported second-line regimens were eminently connected with expanded serum lipid levels. Different examinations have likewise presented comparable outcomes. ${ }^{26}$

Anemia accounted for a total of $17.57 \%$ of total ADRs in this study, which was significantly revealed from patients on zidovudine-based regimens, for example, ZLN and ZLE. Zidovudine is recorded to cause iron deficiency by bone marrow concealment and hindrance of expansion of platelet begetter cells in a time- and dose-dependent mold. ${ }^{27-30}$ Tenofovir-based regimens were anyway observed to be milder in such manner.

Our examination had certain confinements. Being an OPD-based think about, it is very conceivable that some ADRs were missed that were transient or excessively mellow, making it impossible to have troubled the patient to report. Also, the examination was led for a brief period at a solitary focus with a little example estimate checking a small amount of Eastern India populace, in this way the information can't be an agent of national measurements. The examination neglected to recognize the potential indicators of ADRs to ART in HIV-infected patients. The examination may not be an agent to genuine ADR recognition rates as information are to a great extent produced by unconstrained detailing framework as proposed by PvPI. Hazard factor relationship was not examined. Accordingly, nearness of other jumbling factors which could have influenced the ultimate result of the examination which were past the extent of current investigation remains a black out probability.

Despite these limitations, the investigation has certain outstanding qualities. The ADR investigation depended on dynamic reconnaissance of clinical and lab parameters. Also, there was insignificant loss of information because of the forthcoming idea of the examination.

This investigation centers the significance of dynamic ADR reconnaissance. ADR observation is an essential part of checking and assessment in the ART program. The objective of checking is to distinguish the early toxicities 
and antagonistic impacts to help the sheltered utilization of ART, hence enhancing the nature of care and treatment results. Systematic and strong surveillance methods comprising structured pharmacovigilance systems assessing and monitoring safety profile and impact of antiretroviral drugs have thus been advocated.

\section{CONCLUSION}

The investigation empowers to acquire data on the frequency and example of ADRs related with different antiretroviral regimens in PLHIV, in this way reducing its event and protecting the patient populace from avoidable harm. Need of concentrated checking for ADRs in ARTs thus seems to be a mandate. Patient's education on ART-associated ADRs ought to be an essential component of a viable HIV care package so as to facilitate reporting and consequent administration. Presentation of more up to date age drugs with lesser lethality profile in asset restricted settings is a prime order in order to guarantee the arrangement of successful quality care to PLHIV.

Funding: No funding sources

Conflict of interest: None declared

Ethical approval: The study was approved by the Institutional Ethics Committee of Osmania Medical College, Hyderabad, Telangana, India

\section{REFERENCES}

1. Factsheet 2017. UNAIDS. Available at: http://www.unaids. org/en/resources/campaigns/HowAIDSchangedeveryt hing/ factsheet. [Last accessed on 2018 April 18].

2. Kulkarni V. A turning point: The new World Health Organization guidelines for treatment of human immunodeficiency virus infection. Ind J Der Venere Leprol. 2016;82(2):125-7.

3. Mukherjee S, Era N, Saha B, Tripathi SK. Adverse drug reaction monitoring in patients on antiretroviral therapy in a tertiary care hospital in Eastern India. Ind J Pharmacol. 2017;49(3):223-8.

4. Kumarasamy N, Solomon S, Peters E, Amalraj RE, Purnima M, Ravikumar B, et al. Antiretroviral drugs in the treatment of people living with human immunodeficiency virus: experience in a south Indian tertiary referral centre. The Journal of the Association of Physicians of India. 2000;48(4):390-3.

5. Rhodes CM, Chang Y, Regan S, Singer DE, Triant VA. Human Immunodeficiency Virus (HIV) Quality Indicators Are Similar Across HIV Care Delivery Models. InOpen forum infectious diseases, Oxford University Press; 2017;4(1).

6. Luma HN, Choukem SP, Temfack E, Ashuntantang G, Joko HA, Koulla-Shiro S. Adverse drug reactions of Highly Active Antiretroviral Therapy (HAART) in HIV infected patients at the General Hospital, Douala, Cameroon: a cross sectional study. Pan Afri Med J. 2012;12(1).
7. Abdissa SG, Fekade D, Feleke Y, Seboxa T, Diro E. Adverse drug reactions associated with antiretroviral treatment among adult Ethiopian patients in a tertiary hospital. Ethio Med J. 2012;50(2):107-13.

8. Severe P, Jean Juste MA, Ambroise A, Eliacin L, Marchand C, Apollon S, et al. Early versus standard antiretroviral therapy for HIV-infected adults in Haiti. New Eng J Medic. 2010;363(3):257-65.

9. Bonfanti P, Valsecchi L, Parazzini F, Carradori S, Pusterla L, Fortuna P, et al. Incidence of adverse reactions in HIV patients treated with protease inhibitors: a cohort study. Coordinamento Italiano Studio Allergia e Infezione da HIV (CISAI) Group. J Acq Imm Deficie Syndrom (1999). 2000 Mar;23(3):236-45.

10. Dean GL, Edwards SG, Ives NJ, Matthews G, Fox EF, Navaratne L, et al. Treatment of tuberculosis in HIVinfected persons in the era of highly active antiretroviral therapy. Aids. 2002;16(1):75-83.

11. Naranjo CA, Busto U, Sellers EM, Sandor P, Ruiz I, Roberts EA, et al. A method for estimating the probability of adverse drug reactions. Clinical Pharmacology and Therapeutics. 1981;30(2):239-45.

12. The use of the WHO-UMC System for Standardized Case Causality Assessment. Available at: http://www.who-umc.org/Graphics/24734.pdf. [Last accessed on 2016 May 21].

13. Bailey C, Peddie D, Wickham ME, Badke K, Small SS, Doyle-Waters MM, et al. Adverse drug event reporting systems: a systematic review. Bri J Clinic Pharmacol. 2016;82(1):17-29.

14. Hartwig SC, Siegel J, Schneider PJ. Preventability and severity assessment in reporting adverse drug reactions. Ame J Health-System Pharm. 1992;49(9):2229-32.

15. Bhatti AB, Usman M, Kandi V. Current scenario of HIV/AIDS, treatment options, and major challenges with compliance to antiretroviral therapy. Cureus. 2016;8(3).e515.

16. Mayer KH, Chandhiok N, Thomas B. Antiretroviral pre-exposure prophylaxis: A new opportunity to slow HIV spread in India. Ind $\mathbf{J}$ Me Resear. 2016;143(2):125-8.

17. Dandona R, Rewari BB, Kumar GA, Tanwar S, Kumar SP, Vishnumolakala VS, et al. Survival outcomes for first-line antiretroviral therapy in India's ART program. BMC infectious diseases. 2016;16(1):555.

18. Gupta AK, Singh GP, Goel S, Kaushik PB, Joshi BC, Chakraborty S. Efficacy of a new model for delivering integrated TB and HIV services for people living with HIV/AIDS in Delhi-case for a paradigm shift in national HIV/TB cross-referral strategy. AIDS care. 2014;26(2):137-41.

19. Bartlett JA, Chen SS, Quinn JB. Comparative efficacy of nucleoside/nucleotide reverse transcriptase inhibitors in combination with efavirenz: results of a systematic overview. HIV clinical trials. 2007;8(4):221-6. 
20. Spire B, Carrieri P, Garzot MA, L'henaff M, Obadia Y, The Trt-5 Group. Factors associated with efavirenz discontinuation in a large community-based sample of patients. AIDS care. 2004;16(5):558-64.

21. Hawkins T, Geist C, Young B, Giblin A, Mercier RC, Thornton $\mathrm{K}$, et al. Comparison of neuropsychiatric side effects in an observational cohort of efavirenz-and protease inhibitor-treated patients. HIV Clinical Trials. 2005;6(4):187-96.

22. Treisman GJ, Kaplin AI. Neurologic and psychiatric complications of antiretroviral agents. Aids. 2002;16(9):1201-15.

23. Puzantian T. Central nervous system adverse effects with efavirenz: case report and review. Pharmacotherapy: The Journal of Human Pharmacology and Drug Therapy. 2002;22(7):930-3.

24. Young J, Weber R, Rickenbach $M$, Furrer $H$, Bernasconi E, Hirschel B, et al. Research article Lipid profiles for antiretroviral-naive patients starting PIand NNRTI-based therapy in the Swiss HIV Cohort Study. Antiviral therapy. 2005;10:585-91.

25. Ofotokun I, Lennox JL, Smithson SE, Lu C, Easley KA. Liver enzymes elevation and immune reconstitution among treatment-naive HIV-infected patients instituting antiretroviral therapy. Ame J Med Scienc. 2007;334(5):334-41.

26. Ejilemele AA, Nwauche CA, Ejele OA. Pattern of abnormal liver enzymes in HIV patients presenting at a Nigerian Tertiary Hospital. Nig Postg Med J. 2007;14(4):306-9.

27. Miles SA. Hematopoietic growth factors as adjuncts to antiretroviral therapy. AIDS research and human retroviruses. 1992;8(6):1073-80.

28. Miles SA, Golde DW, Mitsuyasu RT. The use of hematopoietic hormones in HIV infection and AIDSrelated malignancies. Hematology/Oncology Clinics. 1991;5(2):267-80.

29. Maggi E, Romagnani S. Role of $\mathrm{T}$ cell derived cytokines in HIV infection. J Bio Regu Homeo Agen. 1995;9(2):37.

30. Groopman JE. Zidovudine intolerance. Rev Infect Dis 1990;12 (5):S500-6.

Cite this article as: Gungam P, Yadav YSK, Junapudi S. A study on adverse drug reactions in patients on antiretroviral therapy in a tertiary care hospital. Int J Basic Clin Pharmacol 2018;7:1882-8. 